\title{
How to compare industrial techniques to Best Available Techniques?
}

\author{
A. Cikankowitz \& V. Laforest \\ Department of Sciences, Information and Technology for the \\ Environment (SITE), Ecole Nationale Supérieure des Mines, \\ Saint-Etienne, France
}

\begin{abstract}
In order to reach an adequate level of environmental protection, the European Union has defined a set of common rules, in the Integrated Pollution Prevention and Control (IPPC) directive, based on Best Available Techniques (BAT) for many pollutant installations. However, there is a problem: the IPPC does not suggest a way to meet BAT requirements for individual industrial units. Therefore, this paper presents the development of our environmental performance assessment methodology in order to transpose and facilitate the implementation of the IPPC directive locally. The approach offers a method to verify overall if an industrial installation conforms with BAT. This methodology is participatory and created with the advice of both industrial (from the metal finishing sector) and governmental (local, regional and national) representatives. This cognitive aid is designed to be updatable to deal with future regulatory and technical change. The participative approach plans to establish a decision support tool that is user friendly, effective and representative of the context involved.

Finally, the case study is ongoing in the metal finishing sector.
\end{abstract}

Keywords: Best Available Techniques (BAT), environmental performances, assessment methodology, IPPC directive, metal finishing.

\section{Introduction}

Industrial production processes account for a considerable share of the overall pollution in Europe. Therefore, the European Union has a set of common rules for the issue of permits and monitoring industrial installations in its Integrated Pollution Prevention and Control (IPPC) directive. According to the French 
Ministry of Ecology and Sustainable Development, about 50000 enterprises are covered by the IPPC Directive in the European Union. In France 5000 installations are classified under IPPC [1].

This Directive is based on four principles: an integrated approach, Best Available Techniques, flexibility and public participation.

In essence, the IPPC Directive is about minimizing pollution from various industrial sources throughout the European Union. Industries covered by Appendix I of the directive are required to obtain an exploitation permit based on environmental criteria from the authorities in the European Union countries [2]. These permits are based on the use of the Best Available Techniques (BAT). Otherwise, these firms run the risk of being shut down. However, the establishment and implementation of BAT present some difficulties that have to be faced by industries and environmental authorities. The IPPC conformity ( 30 October 2007) for existing installations is over. However, the implementation of this directive remains a major concern for most European companies. In France, each technical report under the BAT concept is appraised as incomplete or unfinished by the authorities.

Nowadays there are no coherent, uniform and conceptualized tools to assess the environmental impact of these industrial processes as regards BAT performances defined in the IPPC directive. The industries concerned and the relevant authorities are unable to explain to the manufactures why and by how much the specific technologies would perform the BAT principles. So how can these firms determine if the performance of their existing processes are equivalent to those of BAT?

Our research task is to develop an assessment methodology to help industries to evaluate the efficiency of both production and end of pipe techniques with BAT.

This article is laid out in three parts as follows: the first defines the issue of the BAT principle for industries covered by the IPPC directive. Then, the second deals with the construction of an environmental performances assessment methodology, the L-BAT. This application is to be used in the metal finishing sector. The third part presents the advantages of the L-BAT methodology as well as the work that still needs to be done.

\section{Integrated regulation and BAT concept: purpose and controversy}

\subsection{Integrated regulation and the BAT concept}

The European IPPC directive imposes on high pollution risk industries the use of BAT in order to ensure an effective level of protection for the environment. This European regulation is considered as a model on how to deal with the industrial pollution. Its content is focused on "processes" with the concept of BAT.

The idea of "BAT" is not well defined for a factory site or industrial instillation scales. Moreover, this directive does not specify the use of particular techniques. On the top of this, the European IPPC directive does not impose the 
way that its main principles must be integrated or implemented. In addition, in order to be considered BAT, the evaluation may take into account the technical characteristics of the installation concerned, its geographical location as well as the local environmental conditions [2].

The concept of BAT is defined in Article 2-11 of the IPPC directive. BAT is considered as the "best" meaning that it is the most efficient to reach a high level of environmental protection. The "available" term means that these techniques are tested on a scale which is appropriate in the context of the concerned industrial sector, in technically viable conditions, and also importantly taking into account costs and advantages. Finally, the "techniques" notion involves the processes used, as well as the way that the installation has been conceived, built, fit, exploited as well as considerations of what happens when the plant is no longer in use [2]. So the concept of BAT includes evaluating both the industrial processes and those management practices intended to minimize the firm's environmental impact.

To be regarded as BAT, techniques involved in industries must comply with environmental considerations defined in the appendix IV of the I.P.PC. For instance:

○ use of low-waste technology (consideration 1, C1),

- commissioning dates for new or existing installations (consideration 7, C7),

- duration needed to introduce the best available technique (consideration 8 , C8).

These 12 considerations are not defined homogenously or rigorously [3,4]. So how to use these considerations? How to cross-compare a technique generating little waste to another that limits energy use or to still another with little risk of pollution hazard or accident? Among these 12 considerations, which one should be prioritized in order to be considered the BAT in terms of environmental performance?

In respond to article 16 of the IPPC, experts of various industrial sectors and non-governmental organizations participate in the development of the needed technical documents. These reports, in which the BAT are registered, by sector of activity, are called BREF for Bat REFerence documents. The European BREFs define the emission level associated to the BAT; this means the performances reached by industrial processes (production or end of pipe techniques) [5]. The French regulations define the emission threshold for each activity according to reference values provided by the BREFs. The use of this document by industries is imposed by said regulations. However, in spite of a great deal of effort, several major problems remain: existing installations have not met the standards of the IPPC, nor fulfill the requirements necessary to renew their initial exploitation permit. Finally, there is not even a general comprehension of the concept of BAT.

\subsection{Purpose and controversy}

While BAT is defined at a national, regional or local scale, it is important to take into account not only the priorities of national environmental policies, but also the technical operations, geographical situations and local environmental 
conditions of the installation. However, these aspects are not and cannot be taken into account in the BREFs since they apply to Europe as a whole. At this European level, data provided in this document cannot be precise enough to apply to an individual industrial installation.

Pollutant thresholds for French regulations are based on the emission limit values (ELV) of BAT. If compliance with pollution limits is a factor that justifies using BAT, as specified by the definition of the IPPC directive, it is advisable not to strictly follow to the letter these values. The performance of BAT does not have to be automatically translated into ELV. Indeed, choosing BAT at a local scale involves a multi-criteria analysis based on qualitative criteria of which the ELV is only a part of the quantitative criteria.

Having analyzed some BREFs, more specifically those concerning textile and metal finishing sectors, the assessment and the selection of BAT seem not to be based on accurate nor exhaustive criteria derived from the IPPC but rather on standards too general.

The IPPC directive does not mentioned the manner to comply with the BAT environmental performances through these 12 considerations. Moreover, the local situation of the production sites must be taken into account [2]. It is important to highlight that nowadays there does not exist environmental performance assessment methodologies within the scope of the IPPC directive. However, recent research work has developed an overall approach to determine BAT for each sector's BREF. However these methodologies remain quite general and are hardly implementable in the case of a local installation [6].

\section{The assessment methodology: L-BAT}

\subsection{Steps to set up the methodology}

In order to facilitate the application of the IPPC directive, a method for evaluating processes to validate them as BAT in term of environmental performances has been proposed.

It is divided into three main steps as follows:

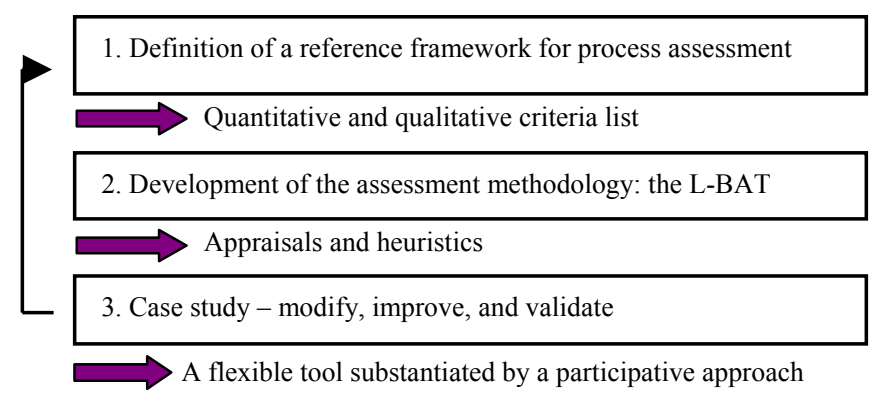

Figure 1: The three steps to set up the methodology. 
The core of this methodology is a structured reference framework from a multi-criteria analysis in order to reach an overall environmental benefit.

The reference framework is made up of environmental criteria and indicators that correspond to the Best Available Techniques (Environmental factors, costs and economic benefit of hazard prevention and environmental protection measures, adaptability of these techniques to local conditions, robustness, etc).

For each studied installation, the constraints linked to cross effects of environmental aspects for the identified processes have also been integrated.

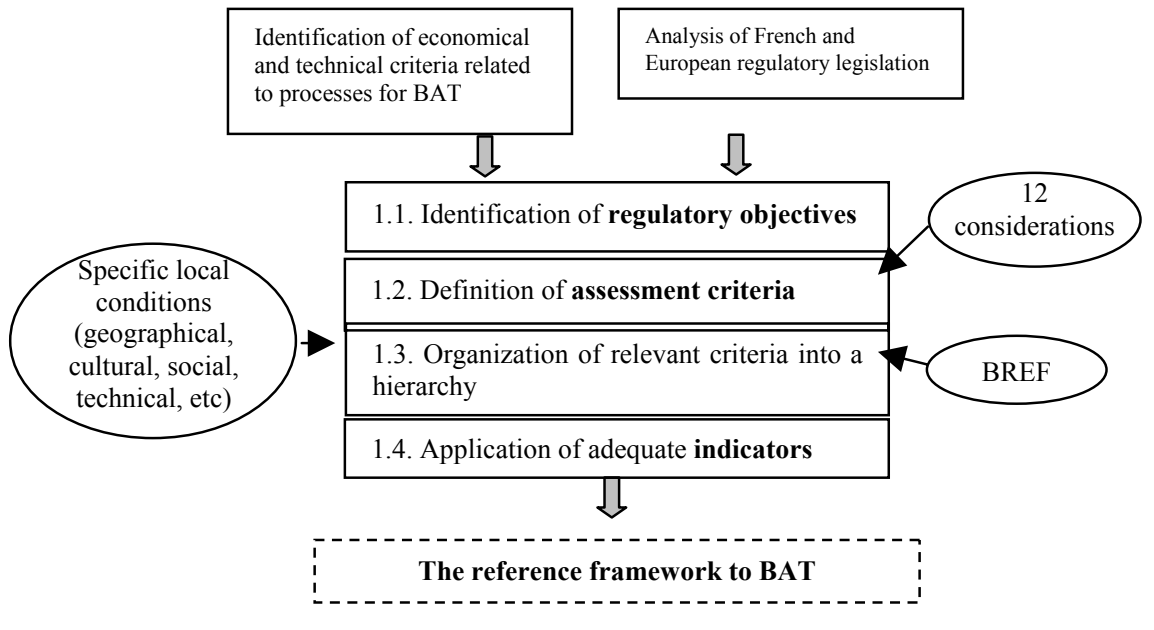

Figure 2: A reference framework.

Then, this methodology has been applied to the production processes and wastewater decontamination processes in metal finishing workshops. Note: this metal finishing sector is subjected to stricter and stricter regulations [7]. Moreover, this tool is to be designed to be user-friendly and efficient for all actors. The creation of individual methodologies for divers sectors of activity has been envisaged. Some criteria seem to be universal for all sectors. However, it appears that each industrial activity has its own particularities.

\subsubsection{Starting point of the L-BAT}

Via an initial case study for IPPC compliance in January 2007, we have developed a preliminary method. The approach is mostly based on qualitative assessment. Four grades of IPPC conformity have been proposed for the evaluation:

- Grade 1: Actions in compliance with BAT given by the BREFs needed for the case study.

- Grade 2: Actions not referred in relevant BREFs for the case study but conforms with the ministerial decree of June $30^{\text {th }}$, 2006. Consequently, conformity with the IPPC directive is guaranteed and thus by extension, with BAT. 
- Grade 3: Actions noncompliant with BAT for relevant BREFs for the case study.

- Grade 4: Actions not concerned with grades 1, 2 or 3.

Then, the L-BAT methodology has been improved by the precisely studying the BREF for this sector.

In order to test the relevance of the L-BAT methodology and to contribute to its further development, a working group was created in November 2006. During the first meeting the relevance of such a methodology was evaluated and approved. Interestingly, some useful ideas for this methodology were introduced.

Importantly, this BAT-working group is composed of industry actors, local, regional and French environmental authorities as well as our research group. Some of them have played a major role of the BREF for the metal finishing industry.

\subsubsection{Content of the L-BAT}

Through the study of French and European regulations in the context of IPPC implementation, four major objectives have been defined and organized according to BAT.

o objective 1: limit and minimize the environmental impact of industrial processes,

o objective 2: prevent or reduce risks,

○ objective 3: meet production quality and industrial strategies

○ objective 4: monitor economic considerations (investment and operation).

The table 1 shows the correlation between assessment criteria and IPPC considerations. This sheds some light on the overall sense of the 12 IPPC considerations, providing them more useful, usable and used by industry. It also permits industries to implicitly conform to the IPPC.

Table 1: $\quad$ Extract of criteria and considerations to characterize BAT, with Cx $(\mathrm{x}=$ the number of the considerations).

\begin{tabular}{|c|c|c|c|c|}
\hline $\begin{array}{c}\text { Identified } \\
\text { Terms }\end{array}$ & Type & Objectives & IPPC Considerations & BAT concept \\
\hline 1. Input & \multirow[b]{2}{*}{ criteria } & OBJECTIVE 1 & $\begin{array}{l}\text { [C9]: consumption rate and nature of } \\
\text { raw materials (including water) used in } \\
\text { the process and energy efficiency }\end{array}$ & \multirow{3}{*}{ BEST } \\
\hline $\begin{array}{l}\text { 2. Emissions } \\
\text { and specific } \\
\text { pollution (noise, } \\
\text { odour) }\end{array}$ & & OBJECTIVE 1 & $\begin{array}{l}\text { [C6]: the characteristics, effects and } \\
\text { volume of the emissions concerned - } \\
\text { [C10]: the need to prevent or minimize } \\
\text { the overall impact for emissions as well } \\
\text { as the risks involved }\end{array}$ & \\
\hline $\begin{array}{l}\text { 3. Prevent } \\
\text { accident }\end{array}$ & criteria & OBJECTIVE 2 & $\begin{array}{l}\text { [C2]: use of less hazardous substances - } \\
\text { [C10] - [C11]: need to limit accidents } \\
\text { and to minimize their consequences }\end{array}$ & \\
\hline
\end{tabular}

\subsection{Which criteria and how to combine them?}

In the frame of this research project, it has been proved that the 12 considerations for the determination of BAT have not been applied neither for the establishment 
of the BREFs, nor at the local level by industries or even environmental authorities. However, it is conceivable to rephrase them by way of evaluation criteria. This is in order to meet to the main regulatory objectives and to try to highlight the need and improve the ease of use of cross-criteria evaluation to determine BAT compliance or equivalence.

Consequently, a lot of general and specific criteria, i.e. local context, are identified, and then included in the determination of BAT:

- quantitative and qualitative criteria (regulatory rejection threshold, prevention, emission management, level of risk, consummation, etc.),

- local context (sensibility of the local environment),

○ technical aspects, specific to studied process, which characterize its environmental aspects in normal run, in integrating its using limits,

- financial capacity of owner (part of investment and relative run to the environment).

In order to formulate the four objectives, an exhaustive list of terms has been organized by criteria, parameters and indicators. In considering the 12 IPPC considerations (appendix IV), this list has been specifically defined to respect these recommendations. These terms were identified for the metal finishing industry. The table 2 presents an extract of some criteria adapted to the objective 1 i.e. the minimizing of the environmental impact.

The organization and the combination of these elements are studied currently through a multi criteria analysis.

Table 2: $\quad$ Extract of criteria organization relative to objective 1.

\begin{tabular}{|c|c|c|c|}
\hline Terms & \multicolumn{2}{|l|}{ Criteria } & Parameters and indicators \\
\hline \multirow{9}{*}{ Prevention } & \multirow{3}{*}{ Consumption } & $\begin{array}{l}\text { Raw material } \\
\text { consumption }\end{array}$ & $\begin{array}{l}\text { Nature, characteristic, amount used, lost } \\
\text { materials flow, toxicity }\end{array}$ \\
\hline & & Water consumption & $\begin{array}{l}\text { Volume of water used, drag out, water } \\
\text { yield }\end{array}$ \\
\hline & & $\begin{array}{l}\text { Energy consumption: } \\
\text { electricity and heating }\end{array}$ & Amount used, power \\
\hline & \multirow{3}{*}{ Recycling } & $\begin{array}{l}\text { Recovery and, } \\
\text { re-use of raw } \\
\text { materials }\end{array}$ & Material yield \\
\hline & & $\begin{array}{l}\text { Reconstitution and } \\
\text { water recycling }\end{array}$ & \\
\hline & & Efficient energy use & \\
\hline & \multirow{3}{*}{$\begin{array}{l}\text { Rejection and } \\
\text { harmful } \\
\text { effects }\end{array}$} & $\begin{array}{l}\text { Industrial wastewater } \\
\text { discharge }\end{array}$ & $\begin{array}{l}\text { Concentration, emission flows, pollutant } \\
\text { substances, decontamination yield }\end{array}$ \\
\hline & & $\begin{array}{l}\text { Industrial air } \\
\text { emissions }\end{array}$ & $\begin{array}{l}\text { Concentration, pollution air flow, nature } \\
\text { (gas, vapor...) }\end{array}$ \\
\hline & & $\begin{array}{l}\text { Industrial waste } \\
\text { production }\end{array}$ & $\begin{array}{l}\text { Kind and volume of waste (quantity), } \\
\text { nomenclature, toxicity }\end{array}$ \\
\hline
\end{tabular}

\subsubsection{Steps of the L-BAT}

Figure 3 shows the steps that new and existing installations have to follow to justify if concepts of BAT are implemented as required by the authorities. 


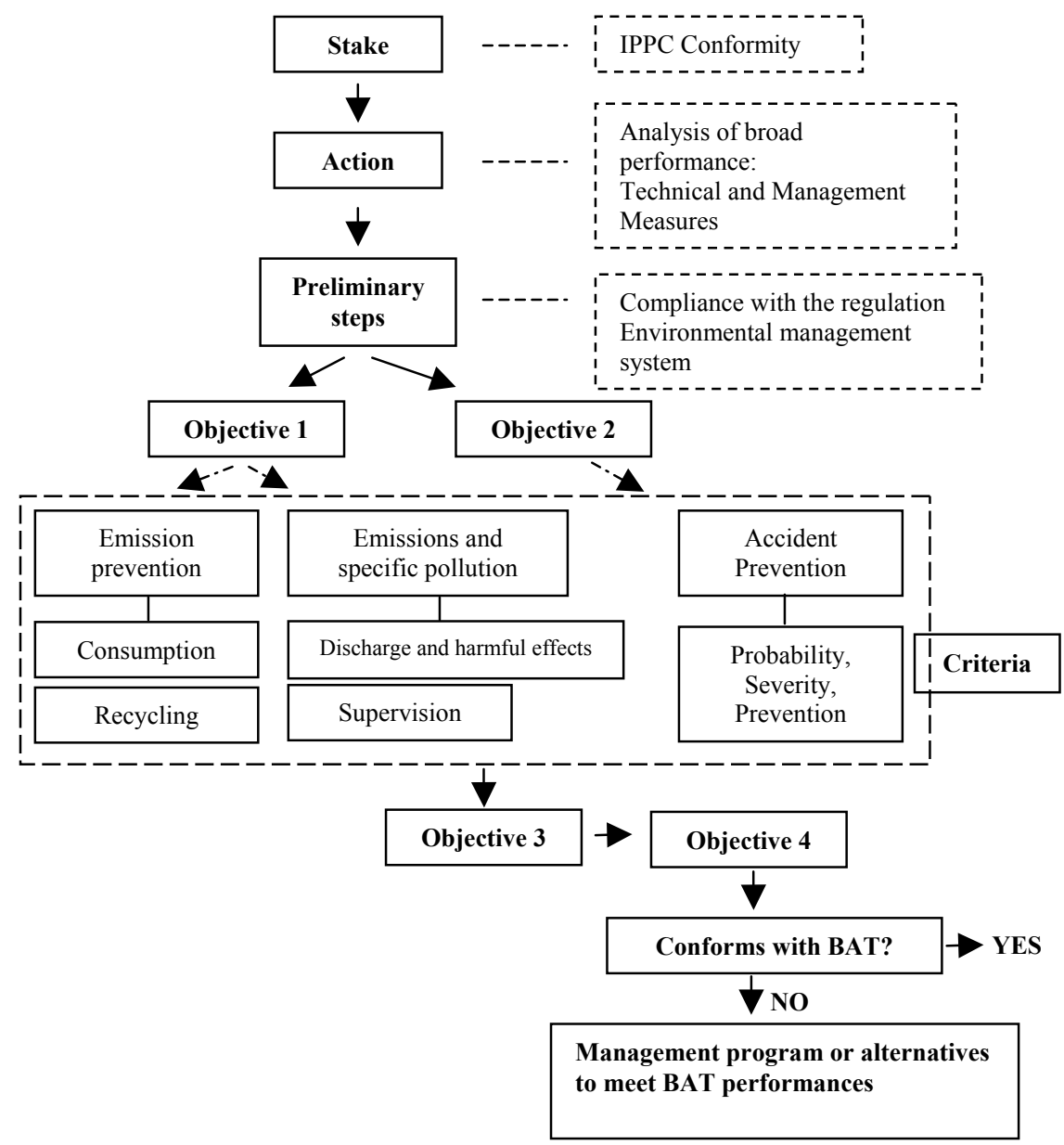

Figure 3: $\quad$ Steps of the L-BAT methodology.

\section{Advantages of the L-BAT methodology}

At first, the proposed tool is not only appropriate for industries in order to facilitate the comparison of techniques (production and decontamination) in terms of BAT environmental performances. Additionally, the authorities may use this approach in order to easily evaluate technical documents.

This methodology demonstrates the contribution of a set of relevant criteria in evaluating if a process should be considered as BAT or to justify a deviation in relation to the BAT performances. This methodology may also ascertain if necessary improvements to reach these BAT objectives are technically and economically viable for the user. 


\subsection{Innovation}

The originality of the L-BAT approach can be demonstrated as follow:

○ study of a decision-making process in terms of pollution, according to works which have been done in its major risks,

○ take part of a voluntary approach (to integrate the needs of involved actors),

○ innovation in proposing a rigorous methodological approach on the base of listing criteria,

○ answers the need for a detailed argumentation when choosing a preventive action as regards BAT efficiency,

○ twofold purpose in its use for both industries and authorities to judge the quality of an updating or an initial industrial permit,

- responsive to technological innovations,

- based on a multi-criteria and multi-actors approach: responding to the difficulty to integrate many and diverse parameters, various objectives and diverging ideas.

\subsection{Tool contributions}

This novel participative approach is both original research wise and crucial to its success. These three points of view (academic, governmental and industrial) underline their own perspectives and often oblige discussion among the participants.

These tool contributions are:

○ integrated approach,

- comparative analysis of environmental performances of processes to BAT at the local level,

- flexible, customized approach,

○ dual deployment: initial, reconsideration, and updating of industrial permit conditions,

- easier communication and dialogue among institutions et industry,

- updatable or configurable for future technological innovations and governmental regulations.

\section{Conclusion}

The European Commission has frequently warned member states about the difficulties for industries to comply with the environmental performance of the BAT concept. The deadline to be in accordance with the IPPC directive is now well past: October $30^{\text {th }}, 2007$. Unfortunately for France, few if any industries are able to justify that they apply BAT or equivalent techniques [8]. Moreover, in the European Union, some installations do not even attempt to implement BAT. The first purpose of some member states was to oblige industries to adopt a unique industrial permit or authorization to operate. France has had this integrated approach since 1976. However, the main difficulty for this country has been in transposing the article 13 of the IPPC directive. Thus, they defined a "working 
report" in which each existing installation has to justify that their techniques perform at a BAT level. This justification or BAT re-evaluation is repeated every 10 years. This is the motivation behind our research project to clarify and strengthen the concept of BAT for both industry and environmental authorities. We propose to accomplish this by developing a clearer and user friendly assessment methodology, the L-BAT (Local-BAT).

This cognitive aid will also answer concretely how difficult it is to apply the BAT at the plant or local level, as defined at the higher European context. In addition, cross-criteria evaluation and other significant factors like diverse technical operations, management policies, local environmental conditions, etc are all incorporated into a broad approach.

Furthermore, our method aims at harmonizing recently initiated approaches in order to justify using BAT at local level. This approach will be customized for tested in the metal finishing industry. One interesting property of this methodology is that it is updatable and thus able to adapt to change in regulation and technology. Our participative approach should guarantee the creation of a decision support tool that is user friendly, effective and representative of the context involved. Hopefully, this tool will be used for continuous improvement and to promote technological innovations in the metal finishing sector.

\section{References}

[1] Bureau Européen pour l'IPPC, “BREF outline and guide”, 2006. Available: http://eIPPCb.jrc.eu

[2] Directive 96/61 EC du Conseil du 24 septembre 1996 relative à "la prévention et à la réduction intégrées de la pollution", JO n L257 du 10/10/1996, pp. 26-40 (art. 2, 6, 9, 13, 16, annexe IV).

[3] H. Chefdebien, "BAT - BREF - IPPC ou encore MTD : les Meilleures Techniques Disponibles”, TSM, juillet-août 2001, N7-8, pp 95-105.

[4] V. Laforest, R. Berthéas, "Integrated environmental regulation - How to define best available techniques?", 9th European Roundtable on Sustainable Consumption and Production, Bilbao, 12-14 May 2004.

[5] Lucas, P., Gislev, M. \& Litten, D. Proc. of the European conference, The Sevilla process: a driver for environmental performance in industry, Stuttgard, 6-7 April 2000 pp. 33-36; 77-87; 91-95.

[6] BAT-center, Flemish Institute for Technological Research (VITO), R. Dijkmans, Methodology for selection of best available techniques (BAT) at the sector level, Journal of Cleaner Production, pp. 1-4, 2001.

[7] Rigaud, J. \& Girad, L.M., Traitement de surfaces, Epuration des eaux, SITS, pp. 9-50; 257-274, 2002.

[8] Questionnaire concernant la mise en œuvre de la directive 96/61/CE relative à la prévention et la réduction intégrées de la pollution (2003-2005 et 20062008), JO de l'Union Européenne, mars 2006, 13p. Available: http://ec.europa.eu/environment/IPPC/index.htm 